\title{
JSRP TASK 22 - CHARACTERISTICS AND PERFORMANCE OF SUPERCRITICAL FLUID EXTRACTION (SFE) IN THE ANALYSIS OF PETROLEUM HYDROCARBONS IN SOILS AND SLUDGES
}

Final Report

Prepared for:

Federal Energy Technology Center

AAD Document Control

U.S. Department of Energy

PO Box 10940, MS 921-143

Pittsburgh, PA 15236-0940

Cooperative Agreement No. DE-FC21-93MC30098

Performance Monitor: Paula Flenory

Prepared by:

Steven B. Hawthorne

Energy \& Environmental Research Center University of North Dakota

PO Box 9018

Grand Forks, ND 58202-9018 


\section{DISCLAIMER}

\section{Portions of this document may be illegible in electronic image products. Images are produced from the best available original document.}




\section{DISCLAIMER}

This report was prepared as an account of work sponsored by an agency of the United States Government. Neither the United States Government, nor any agency thereof, nor any of their employees makes any warranty, express or implied, or assumes any legal liability or responsibility for the accuracy, completeness, or usefulness of any information, apparatus, product, or process disclosed or represents that its use would not infringe privately owned rights. Reference herein to any specific commercial product, process, or service by trade name, trademark, manufacturer, or otherwise does not necessarily constitute or imply its endorsement, recommendation, or favoring by the United States Government or any agency thereof. The views and opinions of authors expressed herein do not necessarily state or reflect those of the United States Government or any agency thereof.

This report is available to the public from the National Technical Information Service, U.S. Department of Commerce, 5285 Port Royal Road, Springfield, VA 22161; phone orders accepted at (703) 487-4650.

\section{ACKNOWLEDGMENT}

This report was prepared with the support of the U.S. Department of Energy (DOE) Federal Energy Technology Center Cooperative Agreement No. DE-FC21-93MC30098. However, any opinions, findings, conclusions, or recommendations expressed herein are those of the authors(s) and do not necessarily reflect the views of DOE.

\section{EERC DISCLAIMER}

LEGAL NOTICE This research report was prepared by the Energy \& Environmental Research Center (EERC), an agency of the University of North Dakota, as an account of work sponsored by DOE. Because of the research nature of the work performed, neither the EERC nor any of its employees makes any warranty, express or implied, or assumes any legal liability or responsibility for the accuracy, completeness, or usefulness of any information, apparatus, product, or process disclosed, or represents that its use would not infringe privately owned rights. Reference herein to any specific commercial product, process, or service by trade name, trademark, manufacturer, or otherwise does not necessarily constitute or imply its endorsement or recommendation by the EERC. 


\section{TABLE OF CONTENTS}

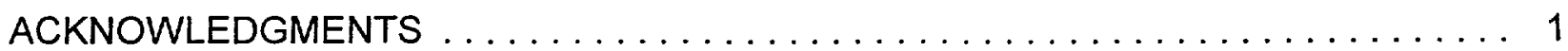

PURPOSE AND MAJOR FINDINGS OF THE RESEARCH $\ldots \ldots \ldots \ldots \ldots \ldots \ldots$

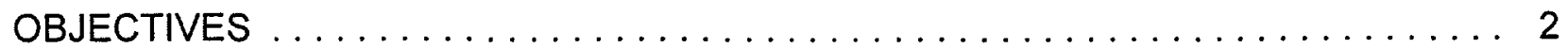

RESULTS AND DISCUSSION ........................... 3

TPH and BTEX Determinations; Gasoline and Diesel Range $\ldots \ldots \ldots \ldots \ldots 3$.

On-line SFE-GC ................................ 3

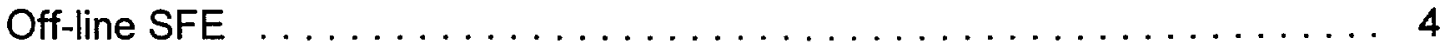

TPH Determinations; Heavy Hydrocarbons $\ldots \ldots \ldots \ldots \ldots \ldots \ldots \ldots \ldots . \ldots . \ldots 6$

PAH Determinations . . . . . . . . . . . . . . . . . . . . . . 6

Practical Aspects and Theoretical Factors Controlling the Application of SFE . . . 8

RECOMMENDATIONS ............................... 10

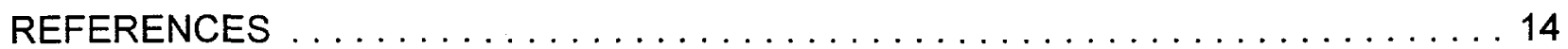




\title{
Characteristics and Performance of Supercritical Fluid Extraction (SFE) in the Analysis of Petroleum Hydrocarbons in Soils and Sludges
}

\author{
Submitted by: \\ Dr. Steven B. Hawthorne \\ Energy and Environmental Research Center \\ University of North Dakota, Grand Forks, ND 58202
}

\section{Acknowledgements:}

We would like to thank API and DOE (METC) for funding these investigations. Roger Claff, Bruce Bauman, and the API Environmental Work Group provided invaluable guidance on the selection of research topics and samples of interest to the petroleum industry. For some of the studies listed below, we would also like to acknowledge the partial financial support from the EPA (EMSL, Las Vegas). In addition, several individuals that provided samples for these studies are acknowledged in the appropriate sections.

\section{Purpose and Major Findings of the Research:}

This project was designed to evaluate and improve SFE methods and instrumentation for the analytical-scale extraction of petroleum hydrocarbons ranging from BTEX components to PAHs and heavy crudes from soils and sludges. The evaluation included the use of "standard" SFE approaches (such as the proposed EPA method for TPH) and commercially-available instrumentation with comparisons to standard liquid solvent extraction methods. Good comparability for TPH (gasoline and diesel range) was demonstrated between conventional Soxhlet extraction and SFE using conditions similar to the proposed EPA SFE method (using both IR and GC/FID quantitation of the extracted hydrocarbons), although SFE yielded higher efficiencies for the more volatile (e.g., BTEX and related alkanes) components because of lower extraction losses than Soxhlet extraction. The use of SFE in the field also gave good agreement for TPH using IR determination for gasoline and diesel-range organics compared to SFE and conventional Soxhlet extractions performed in the lab. Commercial instruments using both solvent trapping (ISCO) and sorbent trapping (Hewlett-Packard) yielded quantitative recoveries (>90\%) of BTEX and gasoline- and diesel-range alkanes as volatile as $C 6$ (for sorbent) and $C 7$ (for solvent trapping), demonstrating that BTEX and TPH determinations can be performed with a single extraction.

An on-line SFE-GC method for gasoline- and diesel-range organics was 
also developed that allows species as volatile as n-butane to be extracted and collected at ca. $100 \%$ efficiency. In addition to allowing quantitative determinations of very volatile species, the SFE-GC method allows sensitive detection limits (e.g., <10 ppb for benzene) for samples as small as $1 \mathrm{gram}$. However, the on-line method is more difficult to perform than the standard SFE methods, and requires modifications to existing SFE and GC instruments.

SFE methods were also developed utilizing high-temperature SFE and the addition of organic modifiers for components that were not efficiently extracted using standard SFE conditions (e.g., heavy hydrocarbons and PAHs). With the combined use of either high SFE temperatures (e.g., $150^{\circ} \mathrm{C}$ ) and/or organic modifiers, the recoveries of heavy hydrocarbons (e.g., heavy resids $>$ C40) were higher than those achieved using Freon-113 Soxhlet extraction las determined by $|R|$. In general, contaminated soils could be extracted as received (i.e., no drying or any other pre-preparation), although samples contaminated with high levels of heavy hydrocarbons (either soils or waste sludges) often caused plugging of some types of SFE flow restrictors. In nearly every case, heating the restrictor and mixing such samples with dispersants and/or drying agents eliminated restrictor plugging.

Practical advantages of SFE included extraction times typically 30-40 minutes (compared to 4 hours or greater for Soxhlet extraction) and total solvent use generally $<10 \mathrm{~mL}$ (compared to $150 \mathrm{~mL}$ for Soxhlet extraction). In nearly all of the samples studied, SFE yielded efficiencies similar to or higher than Soxhlet extraction, however, elevated temperature and/or organic modifiers were often needed to obtain high extraction efficiencies for organics larger than gasoline- and diesel-range. It should be noted that SFE instruments continue to evolve especially in the areas of improved restrictor and collection system designs as well as systems offering automated extraction of up to ca. 20 samples without operator intervention. Such developments should further increase reliability and speed of SFE for petroleum hydrocarbon extractions from soils and sludges.

\section{Objectives:}

The primary goals of this two-year study were to:

* Determine which types of petroleum industry environmental samples and wastes can be extracted using SFE. This includes: 
- Quantitative comparisons to standard (Soxhlet) methods.

- Qualitative descriptions on SFE performance (primarily restrictor plugging).

* Evaluate when presently-available SFE methods are viable alternatives to conventional liquid solvent extraction.

* For samples where SFE conditions have not yet been developed, to determine development needs for SFE extraction and collection conditions. Also, to develop extraction conditions for a wide range of petroleum-based hydrocarbons and PAHs. This effort included:

- Development of two SFE methods that can yield quantitative extraction and recovery of gasoline- to diesel-range organics from soils (thus allowing BTEX and TPH to be determined using a single extraction method).

- Development of quantitative extraction conditions for PAHs and heavier hydrocarbons including heavy crudes and heavy resids.

* Determine hardware development needs based on problems encountered with "real-world" samples, and relate to commercially-available instrumentation.

Results and Discussion:

The first two years of this study resulted in several peer-reviewed publications which summarize methods developed and analytical results. The following discussions are organized by general topic, and the appropriate publications are cited in each section. The reader is referred to these publications for specific details. Since some of the papers are not yet published, draft copies of such papers can be obtained from Steve Hawthorne by contacting him by fax at 701-777-5181.

1. TPH and BTEX Determinations: Gasoline and Diesel Range:

A. On-line SFE-GC:

On-line SFE-GC methodology was developed to allow extraction and 
analysis of organics as volatile as n-butane from solids at ppb detection limits (Burford et al., 1994, Ref 1). A solid-based calibration standard (consisting of several $n$-alkanes and aromatic hydrocarbons spiked onto Tenax-TA) was successfully used to optimize the chromatographic parameters for coupled supercritical fluid extraction - gas chromatography (SFE-GC). A simple and reliable split SFE-GC system was developed utilizing a commercially septumless injector installed on a split/splitless injection port. The high gaseous flow rate generated inside the injection port during the SFE step was accommodated for by using the correct split ratio, so that high $\left(1 \mathrm{ml} / \mathrm{min}\right.$ liquid $\left.\mathrm{CO}_{2}\right)$ SFE flow rates could be used. The use of thick-film columns ( $5 \mu \mathrm{m}$ film thickness) and cryogenic trapping temperatures in the $\mathrm{GC}$ oven as low as $-50^{\circ} \mathrm{C}$ allowed efficient trapping of species as volatile as $n$-butane, acetone, and methylene chloride. The chromatograms obtained using the optimized SFE-GC technique showed good peak shapes (comparable to those obtained using a conventional split injection) and peak area reproducibilities typically $<5 \%$ relative standard deviation.

The SFE-GC method was used for the quantitative extraction and analysis of gasoline and diesel range organics from real world environmental samples (Burford et al. 1994, Ref 2). Petroleum contaminated samples containing gasoline, kerosene, diesel or motor oil (total hydrocarbon content, $\mathrm{mg} / \mathrm{g}$ ca. $168,2,26$, and 10 , respectively) could be quantitatively extracted by a 15 minute SFE-GC extraction using $400 \mathrm{~atm}, 60^{\circ} \mathrm{C} \mathrm{CO}_{2}$. The SFE-GC hydrocarbon recoveries were comparable to those obtained by sonicating the samples in methylene chloride for 14 hours, except for the gasoline recovery which was higher by SFE-GC analysis due to the more efficient collection of the volatile analytes. Gasoline- to diesel-range organics could be quantitatively retained during the SFE step of the SFE-GC analysis using a thick-film $(30-\mathrm{m} \times 0.32-\mathrm{mm}$ I.D., $5-\mu \mathrm{m}$ film thickness) DB-1 column operated at a cryogenic trapping temperature of $-25^{\circ} \mathrm{C}$. Using split SFE-GC operated at a high split ratio (100:1) relatively large $1 \mathrm{~g}$ sample sizes could be investigated, and by using a drying agent (molecular sieve 3A) very wet ( $25 \mathrm{wt} \%$ water) samples could be analyzed without extracted water freezing and plugging in the GC column during the SFE step.

\section{B. Off-line SFE:}

The determination of total petroleum hydrocarbons (TPH) in contaminated soils using supercritical $\mathrm{CO}_{2}$ extraction with quantitation based on infrared spectrometry (SFE-IR) has been compared by performing the SFE-IR measurements in the field and in the laboratory, and by conventional Soxhlet extraction (Hawthorne et al., 1993, Ref. 3). Generator-powered SFE and infrared instruments were operational only about $20 \mathrm{~min}$ after arriving at the 
sampling locations, and no specialized support vehicle was required. SFE-IR analyses of gasoline-, diesel-, motor-oil-, and crude-oil-contaminated soils yielded virtually identical results (less than $10 \%$ variation), whether the samples were extracted and analyzed in the field or in the laboratory. The concentrations of TPH determined using 30-min SFE and 4-h Soxhlet extractions agreed within $20 \%$. Except for the motor-oil-contaminated soil, SFE for 10 min yielded $70-95 \%$ of the quantity that was extracted after $30 \mathrm{~min}$, indicating that short SFE extractions would be useful for minimizing analysis time for field surveys.

Further comparisons for gasoline- and diesel-range organics demonstrated that SFE often yields higher recoveries than Soxhlet extraction (Eckert-Tilotta et al., 1993, Ref. 4). SFE of the gasoline-contaminated sample extracted at 40 $\mathrm{MPa} \mathrm{CO}$ and $65^{\circ} \mathrm{C}$ resulted in higher TPH quantities than those obtained from Soxhlet extraction (134\% SFE vs. Soxhlet), owing to more efficient collection of BTEX (benzene, toluene, ethylbenzene and xylenes) and other volatile components with SFE. Comparable TPH results for the soil extracts were obtained from analytes using gas chromatography with flame ionization detection and infrared spectrometry. Quantitative reproducibility for replicate SFE extracts was good (r.s.d. 2-10\%), and the quantity of Freon-113 solvent was reduced from $150 \mathrm{ml}$ for Soxhlet to $<10 \mathrm{ml}$.

Ideally, the SFE system should be able to extract and collect BTEX and all other gasoline and diesel components so that a single extraction can be used for both BTEX and TPH determinations. Commercially-available SFE systems that use sorbent (Hewlett-Packard) and solvent (ISCO) traps were used for extracting total petroleum hydrocarbons (TPH) from real-world soil samples contaminated with gasoline- or diesel-range hydrocarbons (Yang et al., 1994, Ref 5). Quantitative extractions using both SFE systems were performed at $80^{\circ} \mathrm{C}$ and $340 \mathrm{~atm}$ with a flow rate of $1.5 \mathrm{~mL} / \mathrm{min}$. Both sorbent and solvent trapping could effectively $(>90 \%)$ collect BTEX (benzene, toluene, ethylbenzene, and xylenes). Sorbent trapping yielded quantitative collections $(\geq 88 \%)$ of $n$-alkanes as volatile as $n$-hexane, while the solvent trapping effectively collected $n$-alkanes as volatile as $n$-heptane (pressurized trapping system) or n-octane (normal trapping system). The quantitation of BTEX, TPH, and individual species from contaminated soils obtained by both SFE systems agreed well. However, because of the greater losses of BTEX and the volatile n-alkanes, Soxhlet extraction yielded significantly lower BTEX, TPH, and individual species values than both SFE systems. This study demonstrated that commercially-available SFE instrumentation can be used to determine BTEX and TPH levels using a single extraction. 


\section{TPH Determinations; Heavy Hydrocarbons:}

Heavy hydrocarbons do not extract as readily as gasoline- and dieselrange organics using pure $\mathrm{CO}_{2}$ at conventional temperatures (e.g., $50^{\circ} \mathrm{C}$ ) and pressures (e.g., 340 to $400 \mathrm{~atm}$ ). Therefore, both elevated temperature and the addition of organic modifiers to supercritical $\mathrm{CO}_{2}$ have been evaluated. Supercritical fluid extraction (SFE) with $\mathrm{CO}_{2}$ was used for the determination of total petroleum hydrocarbons (TPH) in real-world fuel-spill soil samples containing heavy fuel oil, diesel fuel, and light crude oil (TPH content, $\mathrm{mg} \mathrm{g}^{-1}$, $\sim 150, \sim 15, \sim 15$, respectively) (Eckert-Tilotta et al., 1993, Ref. 4). Quantitative extraction by SFE was accomplished at 400 atm $\mathrm{CO}_{2}$ and $150^{\circ} \mathrm{C}$ extractor temperature, and TPH results were comparable (within standard deviations) with those obtained by Freon-113 Soxhlet extraction ( $4 \mathrm{~h}$ ) for all samples. Comparable TPH results for the soil extracts were obtained from analytes using gas chromatography with flame ionization detection and infrared spectrometry. Quantitative reproducibility for replicate SFE extracts was good (r.s.d. $2-10 \%$ ), and the quantity of Freon-113 solvent was reduced from 150 $\mathrm{ml}$ for Soxhlet to $<10 \mathrm{ml}$.

Supercritical fluid extraction conditions to quantitatively extract even heavier hydrocarbons from soil were developed which utilize both high temperature $\left(150^{\circ} \mathrm{C}\right.$ ) and an infrared-clear organic solvent (Hawthorne et al., 1994, Ref. 6). SFE with pure $\mathrm{CO}_{2}$ at $65^{\circ} \mathrm{C}$ yielded good recovery for light crude oil components (smaller than ca. C25 alkanes), but did not efficiently extract heavier crude oil components. While raising the temperature during SFE to $150{ }^{\circ} \mathrm{C}$ increased the recovery of the heavier hydrocarbons, the best recoveries were achieved when extractions were performed at $150^{\circ} \mathrm{C}$ after a single addition of perchloroethylene as a modifier. With these conditions, SFE (15 minutes static followed by 15 minutes dynamic extraction) yielded 5 to $45 \%$ higher recoveries than four hours of Soxhlet extraction for soils contaminated with light to heavy crude oils, motor oil, and a heavy residual oil. Based on silica absorption of the extracted polar compounds, both polar organics and non-polar organics were more efficiently extracted by SFE. Since the modifier is added directly to the soil sample, the method does not require either dual pumps or pre-mixed fluids.

\section{PAH Determinations:}

SFE with pure $\mathrm{CO}_{2}$ at conventional temperatures (e.g., $50{ }^{\circ} \mathrm{C}$ ) often cannot quantitatively extract PAHs from well-aged samples. In an effort to increase recoveries, supercritical fluid extraction (SFE) using eight different $\mathrm{CO}_{2}$ 
+ organic modifier mixtures and one ternary mixture $\left(\mathrm{CO}_{2}+\right.$ methanol/toluene $)$ at two different concentrations ( 1 and $10 \% \mathrm{v} / \mathrm{v})$ was performed on two certified reference materials, including polychlorinated biphenyls (PCBs) from river sediment and polycyclic aromatic hydrocarbons (PAHs) from urban air particulate matter (Langenfeld et al., 1994, Ref. 7). The modifier identity was more important than modifier concentration for increasing extraction efficiencies. Acidic/basic modifiers including methanol, acetic acid, and aniline greatly enhanced the extraction of PCBs. Low molecular weight PAHs were best extracted with modifiers including aniline, acetic acid, acetonitrile, methanol/toluene, hexane, and diethylamine. In contrast, modifiers capable of dipole-induced dipole interactions and $\pi$ - $\pi$ interactions such as toluene, diethylamine, and methylene chloride were the best modifiers to use for SFE of high molecular weight PAHs from air particulates. In general, increasing the modifier concentration from 1 to $10 \%(\mathrm{v} / \mathrm{v})$ had little effect on PCB and low molecular weight PAH recoveries, although the recoveries of high molecular weight PAHs from urban air particulate matter were enhanced significantly at the higher modifier concentration. Although there is no definite theory that explains modifier selection for SFE, it appears that modifiers should be selected on the basis of matrix characteristics and the target analytes.

We participated in a mini-round robin using a similar organic modifier method for PAHs in which three soil samples were extracted with SFE and compared to standard sonication (Lopez-Avila et al., 1994, Ref. 8). Interlaboratory reproduciblity was good. The recoveries were typically $>80 \%$ for samples contaminated at $1 \mathrm{mg} / \mathrm{kg}$ or higher, while recoveries typically ranged from 50 to $60 \%$ for samples contaminated at lower levels. It should be noted that we objected to the specified method because it did not utilize a static time to allow the modifier to contact the sample. Based on extensive work with other samples, we are confident that had the static time been added, the recoveries would have been much higher for these samples.

Three other studies (performed under separate funding) have demonstrated that raising the temperature of the SFE step to $200^{\circ} \mathrm{C}$ greatly enhances the extraction of PAHs and other organics, and high temperature SFE typically yields quantitative recoveries of PAHs without the need for organic modifiers (Langenfeld et al., 1993, Ref.9; Hawthorne et al., 1994, Ref. 10). For particularly difficult samples, combined high temperature and modifiers yield the highest recoveries (Yang et al., 1994, Ref. 11). 
IV. Practical Aspects and Theoretical Factors Controlling the Application of SFE:

Efficient methods development using SFE is greatly enhanced by an understanding of the chemical and instrumental parameters and their effect on recoveries. The development of quantitative supercritical fluid extraction (SFE) methods for the recovery of organic pollutants from environmental samples requires three steps: quantitative partitioning of the analytes from the sample into the extraction fluid, quantitative removal from the extraction vessel, and quantitative collection of the extracted analytes (Hawthorne et al., 1993, Ref. 12). While spike recovery studies are an excellent method to develop the final two steps, they are often not valid for determining extraction efficiencies from complex real-world samples such as soils and sediments, exhaust particulates, and sludges. SFE conditions that yield quantitative recoveries of spiked analytes may recover $<10 \%$ of the same analytes from real-world samples, because spiked pollutants are not exposed to the same active sites as the native pollutants. Because of the heterogeneous nature of environmental samples, the partitioning step may be controlled by analyte solubility in the extraction fluid, kinetic limitations, and/or the ability of the extraction fluid to interrupt matrix-analyte interactions. While the interactions that control SFE rates from heterogeneous environmental samples are not well understood, a generalized scheme for developing quantitative SFE methods is proposed based on interactive considerations of the collection efficiencies after SFE, fluid flow parameters in the extraction cell, analyte solubility, extraction kinetics, and analyte-matrix-extraction fluid interactions. The proposed development scheme includes increasing SFE extraction rates by the use of more polar fluids than $\mathrm{CO}_{2}$ such as $\mathrm{CHC}_{1} \mathrm{~F}_{2}$, the addition of organic modifiers to $\mathrm{CO}_{2}$, and the use of high temperature extractions with pure $\mathrm{CO}_{2}$. Validation of quantitative extractions based on multiple extraction methods (SFE followed by liquid solvent extractions) is also described.

Spiked analytes are typically used to determine extraction efficiencies, however, since well-aged analytes may be more strongly bound to sample matrices, spike recoveries may not be valid. To investigate this possibility, the relative extraction rates of native polycyclic aromatic hydrocarbons (PAHs) ranging from naphthalene $(M=128)$ to benzolb]fluoranthene $(M=252)$ and those of spiked deuterated PAHs (d-PAHs) from heterogeneous environmental samples including petroleum waste sludge, urban air particulate matter (SRM 1649), and railroad bed soil were compared using sequential extractions with pure supercritical $\mathrm{CO}_{2}$ or modified $\left(10 \% \mathrm{v} / \mathrm{v}\right.$ methanol) supercritical $\mathrm{CO}_{2}$ and using sonication with methylene chloride (Burford et al., 1993, Ref. 13). Regardless of the spiking method (injection of the spike or suspension of the 
sample in the spiking solution) or aging time (up to $14 \mathrm{~h}$ ), the extraction rates of most of the spiked d-PAHs were substantially (up to 10-fold) higher than those of the same native PAHs. Differences in extraction rates of the spiked and native PAHs were most dramatic for the lower molecular weight PAHs, indicating that relatively volatile species such as naphthalene must be tightly bound in order to remain associated with a real-world sample. In most cases, 30 -min extractions with pure $\mathrm{CO}_{2}$ quantitatively recovered $(>90 \%)$ the spiked deuterated-PAHs, but only extracted ca. $25-80 \%$ of the native PAHs. Similar differences were observed using conventional methylene chloride sonication, demonstrating that spike recovery studies are not valid for developing quantitative extraction methods for heterogenous environmental samples.

While spikes should not be used to determine extraction efficiencies, they are very good to determine collection efficiencies. The collection of petroleum hydrocarbons as volatile as benzene and butane was discussed above and described in detail in references 1,2 , and 5 .

Since some samples encountered in this study required that drying/dispersing agents be added to avoid restrictor plugging during SFE, the use of 21 potential drying agents was investigated (Burford, et al., 1993, Ref. 14). Five (anhydrous and monohydrated magnesium sulfate, molecular sieves $3 \mathrm{~A}$ and $5 \mathrm{~A}$ and Hydromatrix) were able to prevent restrictor plugging by water during off-line supercritical fluid extraction (e.g., 400 atm $\mathrm{CO}_{2}$ at $60^{\circ} \mathrm{C}$ ) by retaining the majority of the water (but generally not the analytes of interest) in the extraction cell. increasing the extraction temperature $\left(e . g .\right.$, to $150^{\circ} \mathrm{C}$ ) or adding a polar modifier [10\% $(\mathrm{v} / \mathrm{v})$ methanol] to the $\mathrm{CO}_{2}$ extraction fluid greatly reduced the amount of water the drying agents retained. However, when $10 \%(\mathrm{v} / \mathrm{v})$ toluene was used for the extraction, the drying agents were able to retain the majority of the water (ca. $80 \% \mathrm{w} / \mathrm{w}$ ). Polar and non-polar pollutants were quantitatively extracted from the wet drying agents (i.e., water present), but nearly all of the drying agents selectively retained at least one of the polar analytes if used dry (i.e., no water present), thus demonstrating the need for a spike recovery study to determine the potential for analyte loss. The successful drying agents eliminated restrictor plugging when used with moderately wet [ca. $20 \%(\mathrm{w} / \mathrm{w})$ water at a $1: 1$ reagent-to-sample ratio] and very wet [ca. $90 \%(\mathrm{w} / \mathrm{w})$ water at $4: 1$ reagent-to-sample ratio] samples without the need to heat the restrictor or the collection solvent.

Fused-silica restrictors used for off-line supercritical fluid extraction (SFE) frequently break when extractions are performed with polar supercritical fluids [e.g., $\mathrm{CHC1F}_{2}$ (Freon 22) or $\mathrm{CO}_{2}$ containing polar modifiers (e.g., methanol)] (Burford et al., 1993, Ref. 15). Securing the fused-silica restrictor inside a 1/16 in. $(1.6 \mathrm{~mm})$ O.D. Stainless-steel tube with an epoxy resin eliminated the restrictor breakage and allowed restrictors to be connected to the extraction cell 
with conventional stainless-steel fittings. The stainless-steel clad fused-silica restrictor was simple and inexpensive to construct, physically robust, and proved ideal for SFE applications since no artifacts from the clad restrictor were detected in the collection solvent. A simple correlation to predict the flow using linear restrictors was also developed that accounts for pressure, temperature, restrictor i.d., and restrictor length (Yang et al., 1994, Ref. 16). This simple correlation allows the proper size of restrictor to be selected for the desired flow rate under different extraction conditions.

\section{Recommendations:}

The results of this study clearly demonstrate that analytical-scale SFE can successfully compete with conventional (e.g., Soxhlet) extraction for the extraction of hydrocarbons from soils and sludges. However, it must be remembered that SFE is not yet as simple to perform as a Soxhlet extraction and, therefore, it is likely that a more highly-trained analyst will be required to obtain good results. SFE methods for gasoline- and diesel-range organics (e.g., the proposed. EPA method) are well-developed and easily implemented using commercial SFE instrumentation. The only reason for slow adaptation of SFE for routine TPH determinations appears to be based on the slow promulgation of the EPA method. For higher boiling species, SFE conditions utilizing elevated temperatures (e.g., $150^{\circ} \mathrm{C}$ ) and/or the addition of organic modifiers are often required to obtain quantitative recoveries (e.g., for alkanes >C30 and PAHs), but such techniques are relatively simple to perform with most commercial instrumentation (and properly-designed "home-built" systems).

On the negative side, some problems still exist with commercial instrumentation, particularly in the areas of restrictor plugging (with particularly "dirty" matrices, e.g., wet sludges with very high extractable organic content) and collection efficiencies of more volatile analytes. The primary differences in commercial instruments occur in these two areas, i.e., the method used to control the $\mathrm{CO}_{2}$ flow rate (the restrictor system), and the method used to collect extracted analytes. Often, seemingly insignificant differences in commercial instrumentation can greatly affect whether a complex sample can be extracted (e.g., whether the restrictor plugs) and whether a particular analyte can be efficiently trapped. While it is unfair to require an instrument supplier to develop a method for a particular application, investigators who wish to evaluate various SFE instrumentation should request two test evaluations. First, the restrictor system should be capable of controlling flow and not plugging while extracting the most complex (e.g., highest water content and highest extractable matrix content) samples that are expected to be 
encountered by the purchaser. Second, the system used to trap the analytes (e.g., sorbent, solvent, or cryogenic trapping) should be demonstrated to quantitatively collect the analytes of interest (particularly the more volatile species) before purchase should be considered. In addition, the majority (but not all) of analytical SFE instruments use sample sizes typically $10-\mathrm{mL}$ or less because of increased reliability for high pressure systems.

It should be noted that, since analytical SFE instrumentation has been commercially-available for only a few years, and since substantial developmental efforts (particularly in automated operation) are just coming to fruition, this report will not attempt to offer purchasing advice. However, the investigator who wishes to utilize the methods described in this report should consider the following results that relate to instrumentation:

1. Both solvent trapping and sorbent trapping were successful with species as volatile as benzene if properly performed. However, both methods can yield very poor collection efficiencies if not properly performed (thus the importance of the collection efficiency evaluation for different vendors' instruments as discussed above).

2. A single addition of modifier to the sample was generally sufficient to increase recoveries of analytes in these investigations where pure $\mathrm{CO}_{2}$ was not successful. Therefore, an SFE instrument should be able to perform extractions in the static (non-flowing) followed by dynamic (flowing) mode.

3. Since a single addition of modifier directly to the sample was generally sufficient (using static followed by dynamic extraction), dual pump systems (which add to instrument costs) to add modifiers were not necessary. However, since future applications may require constant addition of modifier, an instrument should have provisions to add a modifier pump at a future date.

4. We were able to extract all of the sludge and soil matrices, but approximately $1 / 3$ of the samples caused plugging of the restrictors that was severe enough that the sample needed to be mixed with a dispersant (e.g., $40 \mu \mathrm{m}$ "Empore" glass beads) so that the extraction flow was not interrupted. This problem was most severe with samples containing high concentrations of heavy hydrocarbons, and samples with high concentrations of elemental sulfur. In general, soils contaminated with gasoline- and diesel-range organics showed no significant restrictor plugging, even though water contents were as high as $20 \mathrm{wt} \%$. 
Therefore, an SFE system should be evaluated with the range of "realworld" samples that will be extracted.

5. The type of restrictor selected also dictates the $\mathrm{CO}_{2}$ flow rates (and degree of control) that the analyst can select. However, precise flow control had no apparent value in this study. For typical SFE sample sizes (i.e., $<10 \mathrm{~mL}$ ), flows in the range of 1 to $2 \mathrm{~mL} / \mathrm{min}$ of compressed $\mathrm{CO}_{2}$ are usually adequate, and there appears to be no disadvantage to flows that vary by ca. $\pm 30 \%$ from the set-point.

6. For methods development, simpler (and less expensive) SFE instrumentation is often as good as (or better) than more complex (and higher cost) systems. A cost-effective approach to investigating SFE may be to first utilize a simpler system for methods development, and later purchase a more sophisticated automated extraction system when routine methods are implemented.

7. For the samples used in this study, the effect of SFE temperature was more dramatic than pressure. Commercial SFE instruments generally have reasonable upper pressure limits (typically ca. 340 to $600 \mathrm{~atm}$ ), however, temperature limits vary more widely. Based on the results of these studies, upper temperature limits of $\mathrm{ca} .150^{\circ} \mathrm{C}$ (or greater) are desirable.

The results of these investigations also demonstrate that well-aged pollutants can extract at different rates and conditions than recently spiked pollutants. Therefore, spiked organics should be used to test collection efficiencies of the trapping system, but are often not valid to develop extraction conditions (note that the same comments apply to conventional liquid solvent extraction as well as to SFE). The development and testing of an SFE method should utilize "real-world" samples (not spiked samples) to ensure that the aged pollutants are extracted. When the goal is to develop an SFE method that yields recoveries similar to an accepted method (e.g., Soxhlet extraction), the recoveries of the SFE method should be compared to Soxhlet extraction on replicate identical "real-world" samples. When the goal is to develop a method that yields the highest recoveries possible (thus best reflecting the true concentrations), the SFE method should be validated by performing sequential liquid solvent extraction on the sample residue after SFE extraction. If the liquid solvent extraction of the SFE residue contains no significant additional analytes, the SFE method can be considered to yield quantitative recovery.

A final comment on the implementation of SFE is warranted. Sample 
extraction has most often been performed by the least experienced and least trained personnel. During the method development stage, SFE must be considered to be more complex than Soxhlet extraction. Therefore, more experienced personnel will be required to successfully develop quantitative methods (although further developments in automated instruments should allow routine SFE methods to be performed by personnel with minimal training). However, as evidenced by the fact that SFE methods were developed that generally met or exceeded Soxhlet extraction recoveries for all of the samples investigated in this study, SFE can be used to replace liquid solvent extractions for a wide variety of samples when performed by an experienced analyst. It should also be noted that the development of SFE methods can be relatively fast, since extractions used to evaluate various SFE parameters typically require $<30$ minutes to perform (even using simple manual SFE systems). Finally, the demonstrated ability of SFE to reduce liquid solvent usage to 0 to $\mathrm{ca} .15 \mathrm{~mL}$ (depending on the specific collection system used) makes SFE an attractive approach to solving regulatory pressures on liquid solvent use and disposal. 
References:

1. Burford, M.D.; Hawthorne, S.B.; Miller, D.J. "Analysis of Volatile Organics by Supercritical Fluid Extraction Coupled to Gas Chromatography (SFE-GC). Part I. Optimization of Chromatographic Parameters," J. Chromatogr. 1994, in press.

2. Burford, M.D.; Hawthorne, S.B.; Miller, D.J. "Analysis of Volatile Organics by Supercritical Fluid Extraction Coupled to Gas Chromatography (SFE-GC). Part II. Quantitation of Petroleum Hydrocarbons From Environmental Samples." J. Chromatogr. 1994, in press.

3. Hawthorne, S.B.; Miller, D.J.; Hegvik, K.M. "Field Evaluation of the SFEInfrared Method for Total Petroleum Hydrocarbon (TPH) Determinations." J. Chromatogr. Sci. 1993, 31, 26.

4. Eckert-Tilotta, S.E.; Hawthorne, S.B.; Miller, D.J. "Supercritical Fluid Extraction with Carbon Dioxide for the Determination of Total Petroleum Hydrocarbons in Soil," Fuel, 1993, 72, 1015.

5. Yang, Y.; Hawthorne, S.B.; Miller, D.J. "Comparison of Sorbent and Solvent Trapping After Supercritical Fluid Extraction of Volatile Petroleum Hydrocarbons from Soil," J. Chromatogr. in review.

6. Hawthorne, S.B.; Hegvik, K.M.; Yang, Y.; Miller, D.J. "Determination of Heavy Hydrocarbon Contamination Using Supercritical Fluid Extraction (SFE) with Infrared Detection." Fuel, in press.

7. Langenfeld, J.J.; Hawthorne, S.B.; Miller, D.J.; Pawliszyn, J. "Role of Modifiers for Analytical-Scale Supercritical Fluid Extraction of Environmental Samples," Anal. Chem. 1994, 66, 909.

8. Lopez-Avila, V.; Young, R.; Tehrani, J.; Damian, J.; Hawthorne, S.; Dankers, J.; van der Heiden, C. "Mini-Round-Robin Study of a Supercritical Fluid Extraction Method for Polynuclear Aromatic Hydrocarbons in Soils with Dichloromethane as a Static Modifier," J. Chromatogr. 1994, 672, 167-175. 
9. Langenfeld, J.J.; Hawthorne, S.B.; Miller, D.J.; Pawliszyn, J. "Effects of Temperature and Pressure on Supercritical Fluid Extraction Efficiencies of Polycyclic Aromatic Hydrocarbons and Polychlorinated Biphenyls," Anal. Chem., 1993, 65, 338-344.

10. Hawthorne, S.B.; Miller, D.J. "Direct Comparison of Soxhlet and Lowand High-Temperature Supercritical $\mathrm{CO}_{2}$ Extraction Efficiencies of Organics from Environmental Solids," Anal. Chem., 1994, in press.

11. Yang, Y.; Gharaibeh, A.; Hawthorne, S.B.; Miller, D.J. "Effects of Combined Temperature/Modifier on Supercritical $\mathrm{CO}_{2}$ Extraction Efficiencies of Polycyclic Aromatic Hydrocarbons from Environmental Samples," Anal. Chem. 1994, in press.

12. Hawthorne, S.B.; Miller, D.J.; Burford, M.D.; Langenfeld, J.J.; EckertTilotta, S.; Louie, P.K. "Factors Controlling Quantitative Supercritical Fluid Extraction of Environmental Samples," J. Chromatogr. 1993, 642, 301317.

13. Burford, M.D.; Hawthorne, S.B.; Miller, D.J. "Extraction Rates of Spiked versus Native PAHs from Heterogeneous Environmental Samples Using Supercritical Fluid Extraction and Sonication in Methylene Chloride," Anal. Chem. 1993, 65, 1497.

14. Burford, M.D.; Hawthorne, S.B.; Miller, D.J. "Evaluation of Drying Agents for Off-line Supercritical Fluid Extraction." J. Chromatogr. A, 1993, 657, 413-427.

15. Burford, M.D.; Hawthorne, S.B.; Miller, D.J.; Macomber, J. "Construction of a Robust Stainless-Steel Clad Fused-Silica Restrictor For Use in Supercritical Fluid Extraction," J. Chromatogr. 1993, 648, 445-449.

16. Yang, Y.; Hawthorne, S.B.; Miller, D.J. "Estimating Flow Rates for Suband Supercritical Fluid Extractions with Linear Restrictors," J. Chromatogr. 1994, in press. 